\title{
Smooth or Risky Revisit of an Old Malaria Drug for COVID-19?
}

\author{
Priyanka Pahan ${ }^{1} \cdot$ Kalipada Pahan ${ }^{1,2}$
}

Received: 28 April 2020 / Accepted: 4 May 2020 / Published online: 15 May 2020

(C) Springer Science+Business Media, LLC, part of Springer Nature 2020

\begin{abstract}
Hydroxychloroquine (HCQ) is an old medication for malaria. In addition to handling this parasitic disease, HCQ is also used to treat a number of autoimmune disorders including rheumatoid arthritis and systemic lupus erythematosus when other medications are not effective. Recently a new viral infection (COVID-19) is rocking the entire world so much that it has already taken more than 200,000 lives throughout the world within the last two months and the World Health Organization was forced to declare it as a pandemic on March 11, 2020. Interestingly, some reports indicate that this wonder drug may be also beneficial for COVID-19 and accordingly, many clinical trials have begun. Here, we discuss different modes of action (anti-inflammatory, antioxidant, inhibition of endosomal acidification, suppression of angiotensin-converting enzyme 2 or ACE2 glycosylation, etc.) of HCQ that might be responsible for its possible anti-COVID-19 effect. On the other hand, this review also makes an honest attempt to delineate mechanisms (increase in vasoconstriction, inhibition of autophagy, depletion of T cells, etc.) indicating how it may aggravate certain conditions and why caution should be taken before granting widespread repurposing of HCQ for COVID-19.
\end{abstract}

Keywords COVID-19 $\cdot$ Hydroxychloroquine $\cdot$ Inflammation $\cdot$ Oxidative stress $\cdot$ Autophagy $\cdot$ Hypertension

\section{Introduction}

COVID-19 is an infectious respiratory illness caused by the virus strain severe acute respiratory syndrome coronavirus 2 (Sars-Cov-2), a positive sense single strand RNA virus. Based on the sequence similarity ( $\sim 96 \%$ with bat coronaviruses), it has been suggested that COVID-19 is initiated from bat to human transmission or through an intermediary source (Stower 2020; Wu et al. 2020). This disease originated in China has now spread to most countries in the world. Common symptoms include fever, cough, and shortness of breath. Although anyone can get the disease, those over 60 or with preexisting conditions, such as hypertension, obesity, asthma, or diabetes, are more likely to suffer from severe

Kalipada Pahan

Kalipada_Pahan@rush.edu

1 Department of Neurological Sciences, Rush University Medical Center, 1735 West Harrison St Suite Cohn 310, 60612 Chicago, IL, USA

2 Division of Research and Development, Jesse Brown Veterans Affairs Medical Center, Chicago, USA symptoms (Ledford 2020). With a mortality rate of around 4-5\%, COVID-19 is more than 10 times deadlier than the flu. Until now, no effective therapy is available for this global pandemic.

Although quinine, isolated from the bark of cinchona tree in 1820 , is the first approved medication for malaria, Peruvians used extracts of cinchona bark as fever remedies about 400 years back. In some places, cinchona bark extract is still used for malaria, mild influenza, common cold, and swine flu. Chloroquine (CQ) was developed in 1940s as an anti-malarial drug and a substitute for quinine. Later on, a less toxic and a safer derivative of CQ was generated, known as hydroxychloroquine (HCQ). Both CQ and HCQ are widely used medications to treat malaria. In addition to malaria, HCQ is also used for rheumatoid arthritis and lupus (Rempenault et al. 2020; Schrezenmeier and Dorner 2020). Accordingly, WHO has listed HCQ in the 2017 Model List of Essential Medicines as one of the most effective, safe, and economical drugs needed for basic healthcare. Recently, without any successful randomized controlled trials, HCQ is being used to treat and prevent COVID-19 (Principi and Esposito 2020; Taccone et al. 2020). Therefore, we have devoted the following sections to analyze the molecular modes of actions of HCQ in light of the pros and cons of HCQ therapy in COVID-19. 


\section{HCQ Therapy in COVID-19}

Two separate studies used SARS-CoV-2-infected African Green monkey kidney Vero cells to demonstrate that HCQ is effective in inhibiting SARS-CoV-2 infection in vitro (Liu et al. 2020a; Yao et al. 2020). Accordingly in multicenter clinical trials conducted in China, HCQ exhibits efficacy and acceptable safety in attenuating COVID-19-associated pneumonia (Gao et al. 2020). In another small open-label nonrandomized clinical trial from France, it has been shown that HCQ is associated with the reduction of viral load (Gautret et al. 2020). Accordingly, Food and Drug Administration has authorized clinicians in USA to prescribe HCQ for hospitalized patients with COVID-19 (Lenzer 2020). However, from a recent analysis of 368 patients in U.S. Veterans hospitals, it has been found that HCQ does not provide any benefit, but more side effects and deaths, indicating a possible HCQ puzzle in COVID-19.

\section{Mechanisms by which HCQ Could be a Medical Friend of COVID-19 Patients}

Whether HCQ has anything to do with COVID-19 or not, HCQ is fully capable of modulating many cellular signaling pathways, which are relevant to COVID-19 pathology.

Inhibition of Proinflammatory Molecules by HCQ Inflammation is not always bad as human bodies fight off an infection, injury or insult with the help of inflammation. However, sometimes, when inflammation is initiated, it goes beyond control leading to prolonged inflammation to secrete a wide range of proinflammatory molecules that ultimately cause tissue damage and death. It is becoming clear that a subgroup of patients with severe COVID-19 symptoms suffer from cytokine storm and broad-spectrum inflammatory events (Mehta et al. 2020). It has been shown that COVID-19 patients in the ICU have higher plasma levels of interleukin-2 (IL-2), IL-7, granulocyte-colony stimulating factor (GSCF), interferon- $\gamma$ inducible protein 10 (IP-10), monocyte chemoattractant protein 1 (MCP1), macrophage inflammatory protein 1- $\alpha$ (MIP1- $\alpha$ ), and tumor necrosis factor- $\alpha$ (TNF- $\alpha$ ) as compared to non-ICU patients (Huang et al. 2020). According to Chen et al. (Chen et al. 2020), severe COVID19 cases more frequently have dyspnea, lymphopenia, and hypoalbuminemia, with higher levels of alanine aminotransferase, lactate dehydrogenase, C-reactive protein, ferritin, and D-dimer as well as markedly higher levels of IL-2R, IL-6, IL10 , and TNF- $\alpha$. Therefore, controlling proinflammatory cytokines may be beneficial for COVID-19 patients in the ICU. Interestingly, HCQ treatment has been shown to control the overproduction of IL-1 $\beta$ and GM-CSF in acute rheumatic fever (Kim et al. 2018) and to reduce the level of IL-6 in patients with rheumatoid arthritis (Batun-Garrido et al. 2018).
The p38 mitogen-activated protein kinase (p38MAPK) is a key protein kinase to regulate the transcriptional activity of NF- $\mathrm{KB}$ and expression of proinflammatory molecules (Watanabe et al. 2004; Saha and Pahan 2006a, b). Interestingly, CQ inhibits the activation of p38MAPK to inhibit the induction of proinflammatory cytokines in THP-1 cells (Seitz et al. 2003). Moreover, NADPH oxidase (NOX2), a multimeric complex of gp91phox, p67phox, p47phox, p22phox, and small G protein Rac, catalyzes the production of superoxide to play an important role in oxidative stress and inflammation (Bylund et al. 2010). The gp91phox is the catalytic subunit of NOX2 and interestingly, HCQ attenuates the translocation of gp91phox to the membrane (Muller-Calleja et al. 2017), leading to the inhibition of oxidative stress and proinflammatory signaling pathways. Therefore, CQ/HCQ treatment may be beneficial for COVID-19 patients via its antioxidant and anti-inflammatory properties (Fig. 1).

Reduction of Endosomal Acidification by HCQ Viral entry into the host cells is probably the most important element in viral infection, and endosomal acidification plays a critical for the entry of enveloped viruses into the cell (Yang et al. 2004) where at low $\mathrm{pH}$, different enzymes disrupt the viral particle to liberate the infectious nucleic acid. On the other hand, HCQ, being a weak base, accumulates within acidic vesicles, such as endosome and lysosome, increases the $\mathrm{pH}$ and halts the $\mathrm{pH}$-dependent endosome-mediated viral entry. Khan et al. (Khan et al. 2010) have demonstrated that prior treatment with CQ significantly protects Vero cells against Chikungunya virus through the prevention of endocytosis and/or endosomal acidification. Accordingly, in a double-blind, randomized, placebo-controlled trial, CQ exhibits efficacy in lowering the viral load and treating dengue in Vietnamese adults (Tricou et al. 2010). In case of SARS-CoV-1, Wang et al. have shown that the fusion of viral and endosomal membranes leading to the release of the viral genome into the cytosol occurs at acidic $\mathrm{pH}$ (Wang et al. 2008). In recent cell culture studies, both CQ and HCQ also efficiently reduces SARS-CoV-2 infection (Liu et al. 2020a). Therefore, HCQ is expected to increase endosomal $\mathrm{pH}$ and lower viral load in patients with COVID19 (Fig. 2).

Suppression of ACE-2 Glycosylation by HCQ Treatment Angiotensin-converting enzyme 2 (ACE2) capable of degrading angiotensin II (AngII), the main effector of the classical renin-angiotensin system, and generating Ang1-7, plays an important role in the pathophysiology of cardiovascular diseases (Vickers et al. 2002; Zaman et al. 2002). This is a cell surface receptor, and lung, heart and kidney are very rich in ACE2 (Zaman et al. 2002). However, recently, ACE2 came to the forefront due to another reason and that is the requirement of this receptor by COVID-19 


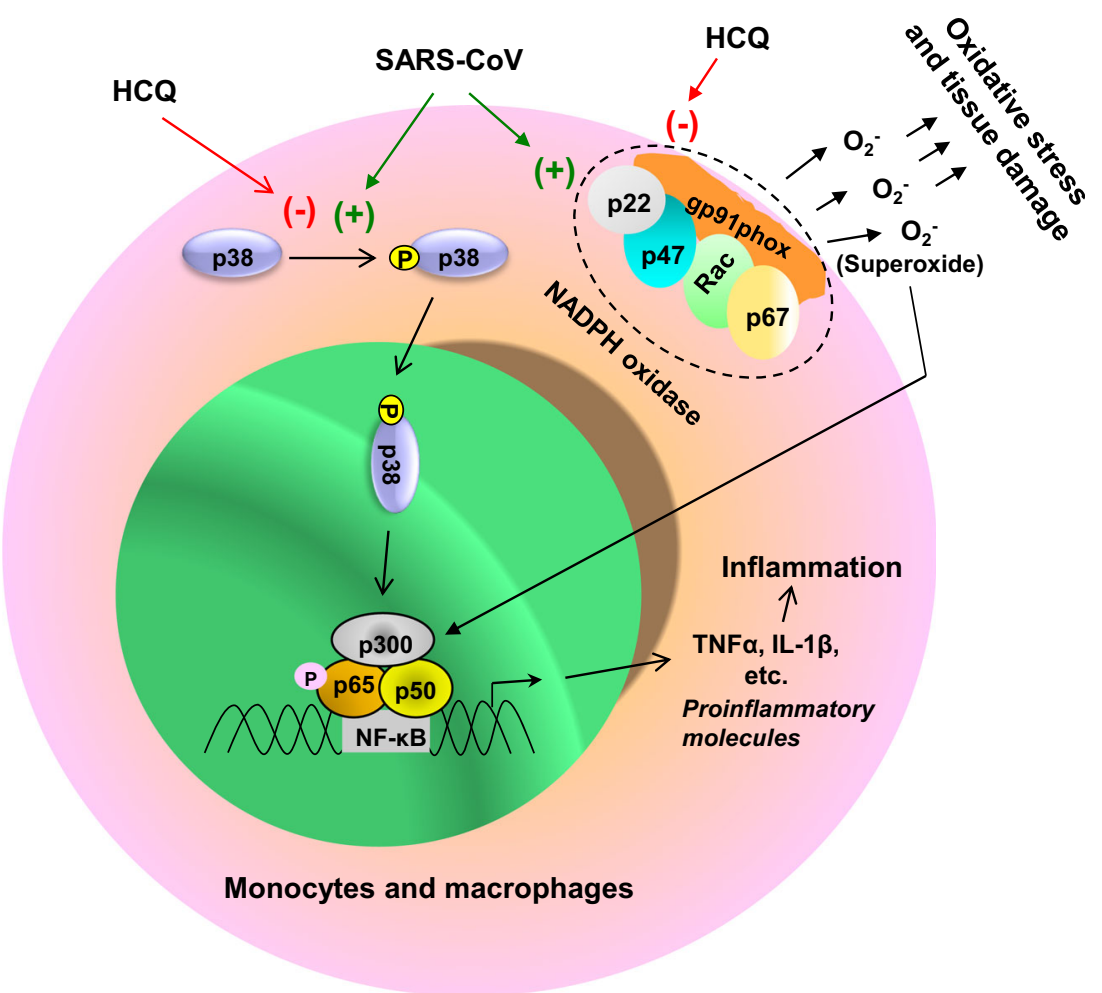

Fig. 1 HCQ exhibits antioxidant and anti-inflammatory effects. SARS-CoV causes the phosphorylation and activation of p38 mitogenactivated protein kinase (p38). Then activated p 38 causes the activation of classical heterodimeric (p65:p50) NF- $\mathrm{kB}$, a proinflammatory transcription factor. Together with activated p300 (a proinflammatory histone acetyl transferase), the NF- $\mathrm{KB}$ then binds to the promoter of different genes ultimately leading to the transcription and production of different proinflammatory molecules (e.g. tumor necrosis factor alpha or $\mathrm{TNF} \alpha$, interleukin- $1 \beta$ or IL- $1 \beta$, etc.). HCQ inhibits the phosphorylation of $\mathrm{p} 38$ to attenuate the production of different proinflammatory cytokines. Again, activation of NADPH oxidase (a pentameric complex of gp91phox, p67phox, p47phox, p22phox, and Rac) produces superoxide radicals to cause oxidative stress and the activation of NF- $\mathrm{KB}$ for inflammation. HCQ prevents the translocation of gp91phox to the membrane and thereby inhibits the activation of NADPH oxidase to reduce oxidative stress and inflammation

physiological vasoconstrictor (AngII) to a vasodilator (Ang17) (Fig. 3a). This beneficial heptapeptide (Ang1-7) functions through its receptor Mas to exhibit vasodilatory/antiproliferative activities (Wang et al. 2012). Moreover, Ang1-7 is also capable of inhibiting myocardial NADPH oxidase leading to a decrease in myocardial oxidative stress and inflammation (Bodiga et al. 2011). Therefore, ACE2 is considered as a negative regulator of AngII-induced myocardial hypertrophy, fibrosis, and diastolic dysfunction. It has been demonstrated that the deletion of the ACE2 gene in mouse results in abnormal heart function (Oudit et al. 2007). ACE2-deficient mice also exhibit increased level of AngII in plasma and heart leading to cardiac dysfunction (Yamamoto et al. 2006; Oudit et al. 2007). Accordingly, recombinant human ACE2 also displays beneficial effects in a clinically relevant model of pressure-overload induced heart failure (Basu et al. 2017). Therefore, in general, inhibition of ACE2 leads to an increase in vaconstrictor and a decrease in vasodilator, ultimately increasing the chances of inducing and/or aggravating cardiovascular diseases such as heart attacks, stroke, or arrhythmia. As a result, by suppressing ACE2, HCQ may pose risks for patients with preexisting cardiovascular issues. 
Fig. 2 Reduction of viral load by HCQ. Upon glycosylation, angiotensin converting enzyme 2 (ACE2) translocates to the membrane. SARS-CoV2 uses the glycosylated ACE2 receptor to enter into the cell. The fusion of viral and endosomal membranes leading to the release of the viral genome into the cytosol occurs at acidic $\mathrm{pH}$. The genomic RNA is translated to proteins to assemble copies of the virus followed by exocytosis of SARS-CoV2 and infection of neighboring cells. HCQ inhibits the glycosylation of ACE2 receptors and increases the $\mathrm{pH}$ to prevent the fusion of viral and endosomal membrane

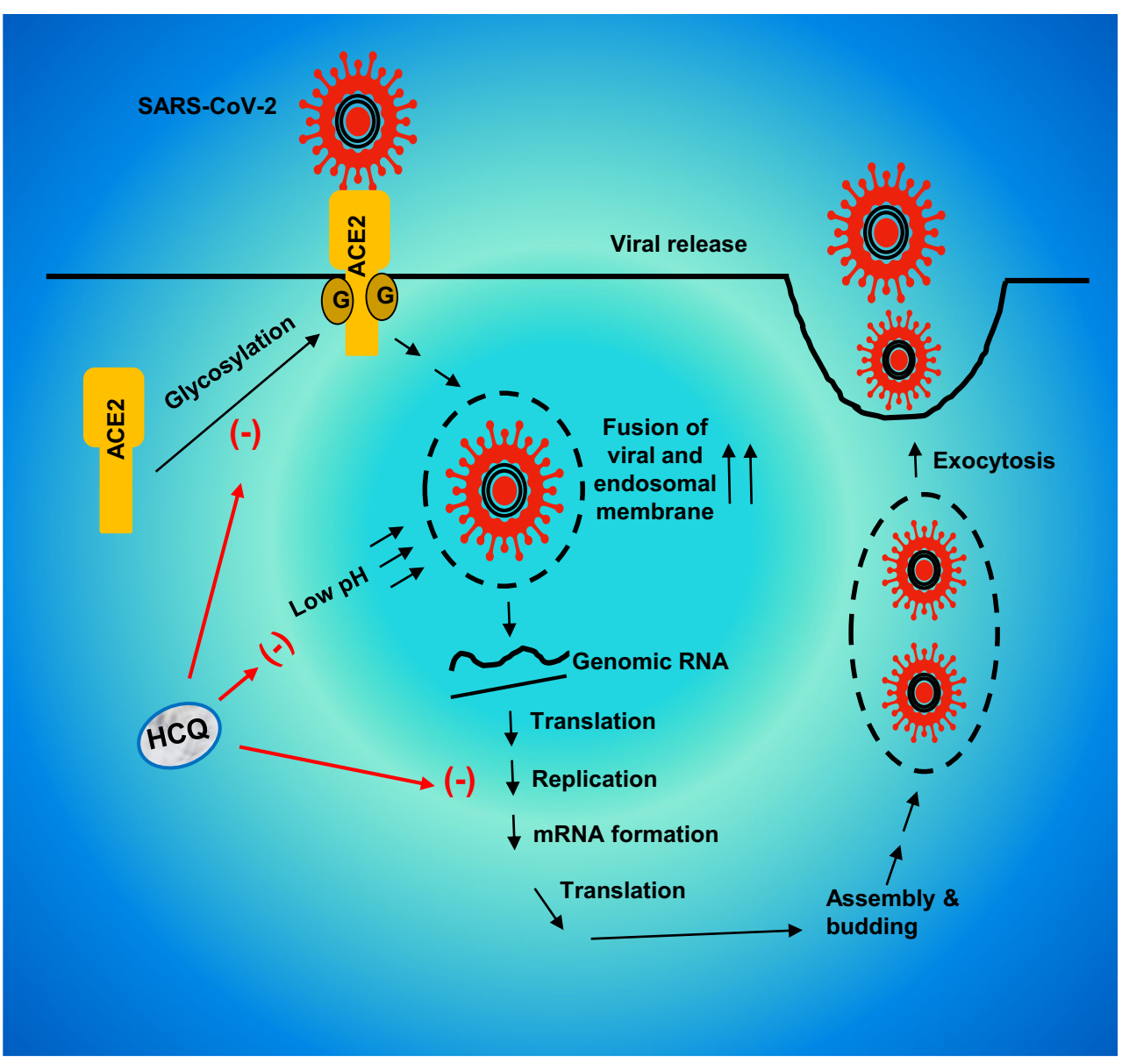

Attenuation of T Cell Proliferation by HCQ It has been found that the $\mathrm{CD}^{+}$and $\mathrm{CD}^{+} \mathrm{T}$ cell counts are closely related to disease severity and clinical outcome in COVID-19 patients and that lower $\mathrm{T}$ cell counts are associated to ICU admission (Liu et al. 2020b). Accordingly, as expected, decreased IFN- $\gamma$ expression in CD4 $+\mathrm{T}$ cells are associated with severe COVID-19 cases (Pedersen and Ho 2020). In addition to T cells, number of B cells and natural killer (NK) cells also decrease in COVID-19 patients with severe cases than mild ones (Wang et al. 2020). Therefore, maintaining the homeostasis and classical functions of $\mathrm{T}$ cells is important for the recovery of severe COVID-19 patients. However, according to Landewe et al. (Landewe et al. 1995), CQ inhibits the proliferation of $\mathrm{T}$ cells at least partly through interfering with the production of IL-2 protein and the induction of IL-2 mRNA. Accordingly, by attenuating $\mathrm{T}$ cell proliferation, $\mathrm{CQ} / \mathrm{HCQ}$ may exhibit adverse effect on severe COVID-19 patients (Fig. 3b).

Suppression of Autophagy by HCQ Phagocytosis, a crucial arm of our innate immune system, plays an important role in the regeneration of new healthy cells via repossessing, removing and recycling dead cells and other cellular debris. It is crucial for the endosomal $\mathrm{pH}$ to be low so that old damaged cells can be removed during autophagy. However, a number of studies have shown that CQ and HCQ can interfere lysosomal function and autophagy at multiple steps (Sundelin and Terman 2002; Frustaci et al. 2012; Mauthe et al. 2018). Lysosomal $\mathrm{pH}$ plays a critical for lysosomal enzymes to be active in hydrolysis. It has been demonstrated that CQ and HCQ increase the $\mathrm{pH}$ of endosomal compartments to weaken the maturation of lysosomes and autophagosomes (Fox and Kang 1993; Mauthe et al. 2018). Palmitoyl-protein thioesterase 1 (PPT1) is an enzyme involved in the catabolism of lipid-modified proteins and Rebecca et al. (Rebecca et al. 2019) have described that HCQ can bind and inhibit PPT1 activity.

In addition to removing dead cells, autophagy is expected to clear Lewy body pathology in Parkinson's disease (PD), dementia with Lewy bodies (DLB) and multiple system atrophy (MSA). Autophagy is also important in lowering plaques and tangles in Alzheimers's disease (AD), progressive supranuclear palsy (PSP) and frontotemporal dementia (FTD) and reducing huntingtin inclusions in Huntington's disease (HD). Since aging is the most important risk factor of these neurodegenerative disorders and aged people are also more susceptible to COVID-19, it is possible that HCQ 


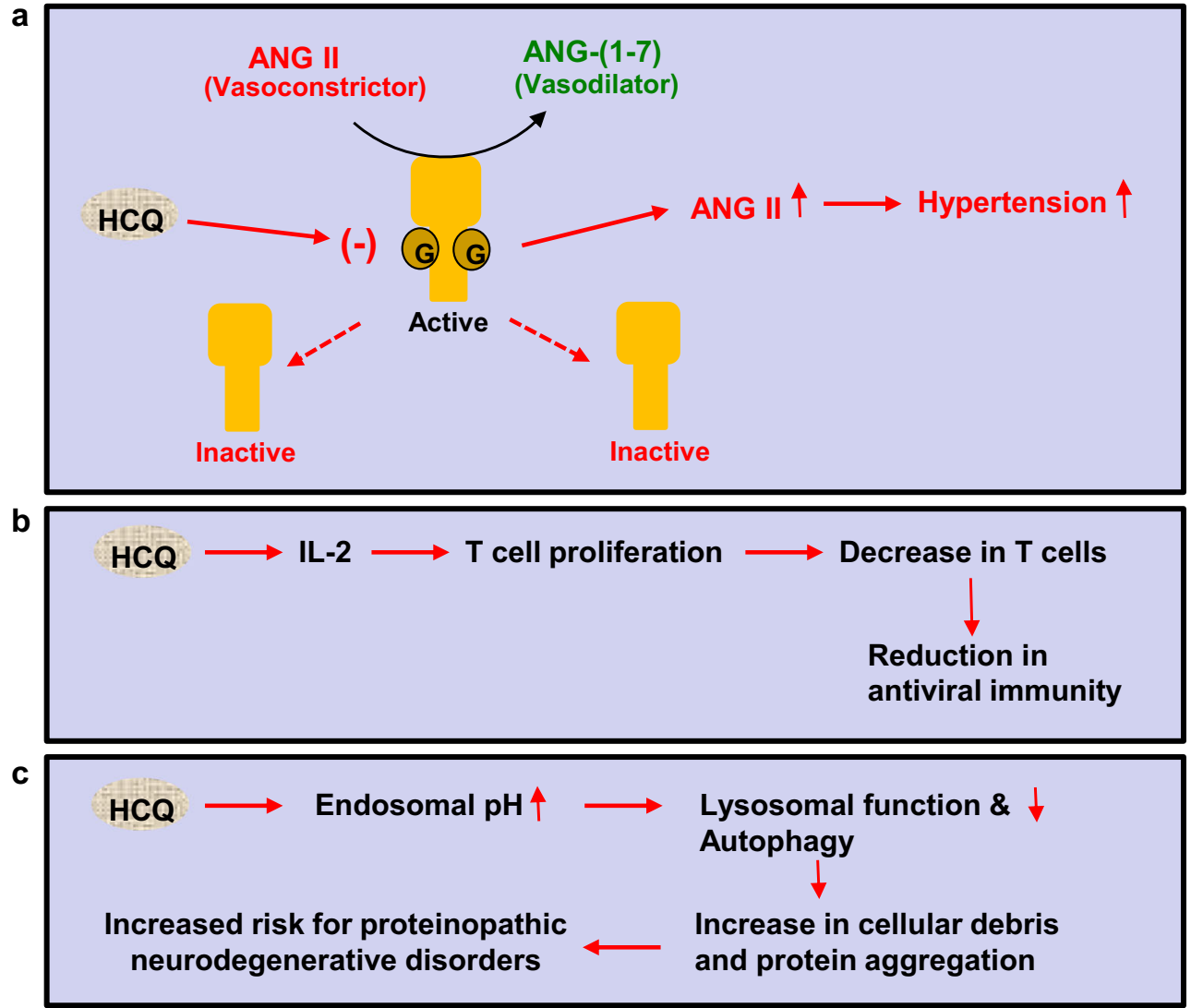

Fig. 3 Possible deleterious effects of HCQ. a ACE2 catalyzes the production of angiotensin 1-7 (a vasodilator) from angiotensin 2 (a vasoconstrictor). The ACE2 receptor needs to be glycosylated to be active. HCQ can inhibit glycosylation and therefore inactivate the receptor, ultimately causing greater amount of vasoconstrictor to remain active. This can potentially be harmful for patients with hypertension and cardiovascular problems. b IL-2 is needed for T cell proliferation. This allows the immune system to fight off viral infections. HCQ can decrease the proliferation of $\mathrm{T}$ cells via inhibiting the production of IL-2, ultimately affecting the body's anti-viral immunity. $\mathbf{c}$ By increasing the endosomal $\mathrm{pH}$, HCQ decreases autophagy. Therefore, damaged cell components and proteins would aggregate and this can increase the risk of neurodegenerative disorders in which abnormal protein aggregation is the cardinal feature treatment may increase the risk of different neurodegenerative disorders in older individuals and aggravate protein aggregation in patients with PD, DLB, MSA, AD, PSP, FTD, or HD (Fig. 3c). Moreover, there are about 150 different

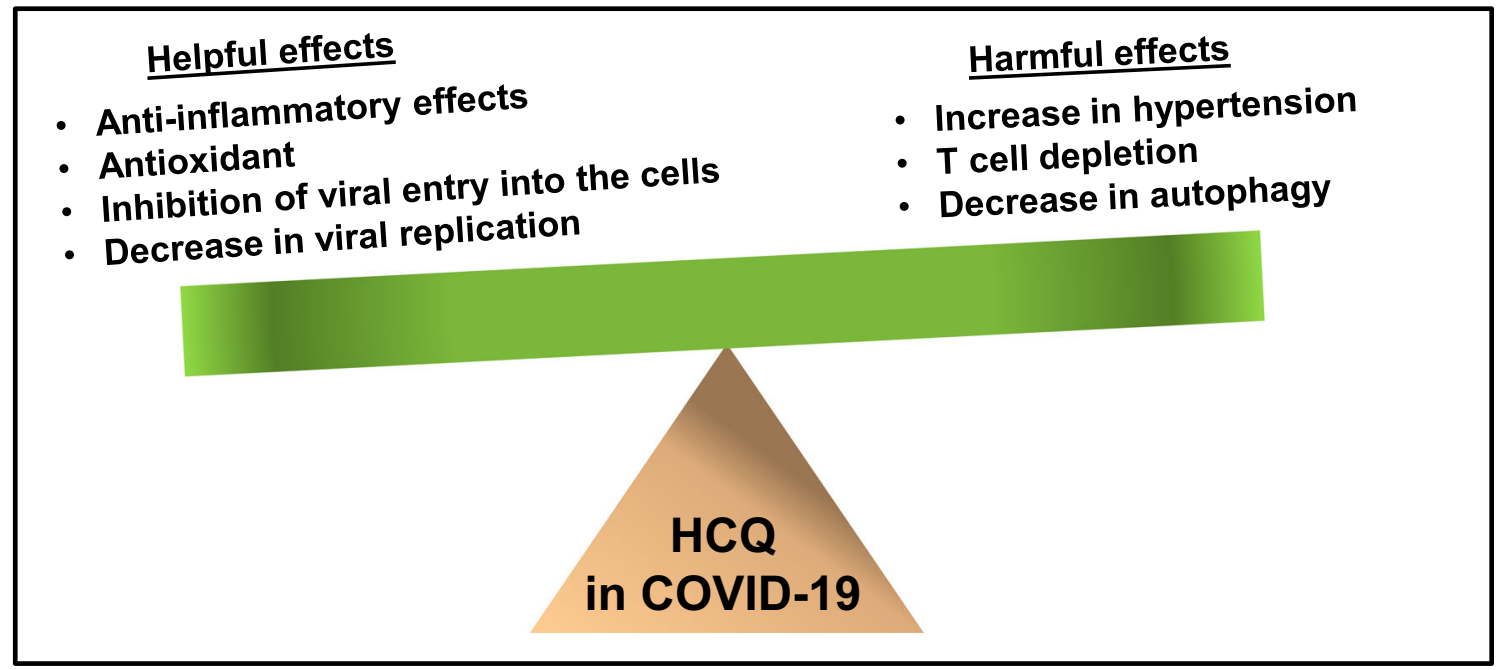

Fig. 4 Balance between helpful and harmful effects of HCQ for COVID-19 
lysosomal storage disorders (LSD) and decrease in autophagy to any extent (Ballabio and Bonifacino 2020) by HCQ will be detrimental in patients with LSD and may be detrimental even in the carriers of LSD.

\section{Concluding Thoughts}

At present, developing effective therapies against COVID-19 is of the highest priority. Important aspects of COVID-19 treatment are to inhibit viral entry into host cells and reduce viral load. From these criteria, HCQ fits very well as a possible anti-COVID-19 drug (Fig. 4). Moreover, oxidative stress and inflammation are important pathological aspects of many human disorders, which are also seen in COVID-19 cases. HCQ is also right there to take care of these two comorbid issues. However, by inhibiting the function of ACE2, this so-called miracle drug may augment vasoconstriction and worsen cardiovascular problems in persons with preexisting hypertension, obesity and heart disease. This is an important issue as hypertension and obesity are very common in USA. Loss of T cells has become an important feature of severe COVID-19 patients suffering from acute respiratory problems. Since HCQ inhibits the proliferation of T cells, it may not bring good news for COVID-19 patients who are in the ICU. Moreover, the aged population is more susceptible to COVID-19 severity than the younger ones. Since proteinopathy and neurodegeneration are also common in older population, HCQ may increase the risk of proteinopathic neurodegenerative diseases in susceptible persons via suppressing autophagy.

Therefore, at present, there are two distinct pictures regarding the involvement of HCQ in the treatment of COVID-19 patients. First, due to its well-known anti-viral, antiinflammatory and antioxidant effects, HCQ may be beneficial for COVID-19 patients who do not have a history of hypertension, obesity and heart problems. Second, HCQ may not be safe for COVID-19 patients who have or are at risk for cardiovascular diseases or may lead to unfavorable outcome in older patients with other preexisting conditions. However, the patients who would suffer from severe COVID-19 and would need a treatment are those with comorbidities. Therefore, caution must be taken before prescribing HCQ for severe COVID-19 patients. It would be very nice to see if through the ongoing clinical trials, HCQ having a rich history of treating many human diseases including malaria, lupus and rheumatoid arthritis also becomes effective in treating COVID-19 patients (Fig. 4).

Acknowledgements This study was supported by grants from NIH (AG050431, AG050431S1 and NS108025), the Zenith Fellows Award (ZEN-17-438829) from Alzheimer's Association and a merit award (1I01BX003033) from US Department of Veterans Affairs to KP. Moreover, KP is the recipient of a Research Career Scientist Award (1IK6 BX004982) from the Department of Veterans Affairs.

\section{Compliance with Ethical Standards}

Conflict of Interest None.

\section{References}

Ballabio A, Bonifacino JS (2020) Lysosomes as dynamic regulators of cell and organismal homeostasis. Nat Rev Mol Cell Biol 21:101118

Basu R, Poglitsch M, Yogasundaram H, Thomas J, Rowe BH, Oudit GY (2017) Roles of Angiotensin Peptides and Recombinant Human ACE2 in Heart Failure. J Am Coll Cardiol 69:805-819

Batun-Garrido JAJ, Salas-Magana M, Juarez-Rojop IE (2018) Association between leptin and IL- 6 concentrations with cardiovascular risk in patients with rheumatoid arthritis. Clin Rheumatol 37: 631-637

Bodiga S, Zhong JC, Wang W, Basu R, Lo J, Liu GC, Guo D, Holland SM, Scholey JW, Penninger JM, Kassiri Z, Oudit GY (2011) Enhanced susceptibility to biomechanical stress in ACE2 null mice is prevented by loss of the p47(phox) NADPH oxidase subunit. Cardiovasc Res 91:151-161

Bylund J, Brown KL, Movitz C, Dahlgren C, Karlsson A (2010) Intracellular generation of superoxide by the phagocyte NADPH oxidase: how, where, and what for? Free Radic Biol Med 49: 1834-1845

Chen G, Wu D, Guo W, Cao Y, Huang D, Wang H, Wang T, Zhang X, Chen H, Yu H, Zhang X, Zhang M, Wu S, Song J, Chen T, Han M, Li S, Luo X, Zhao J, Ning Q (2020) Clinical and immunological features of severe and moderate coronavirus disease 2019. J Clin Invest

Fox RI, Kang HI (1993) Mechanism of action of antimalarial drugs: inhibition of antigen processing and presentation. Lupus 2(Suppl 1):S9-S12

Frustaci A, Morgante E, Antuzzi D, Russo MA, Chimenti C (2012) Inhibition of cardiomyocyte lysosomal activity in hydroxychloroquine cardiomyopathy. Int J Cardiol 157:117-119

Gao J, Tian Z, Yang X (2020) Breakthrough: Chloroquine phosphate has shown apparent efficacy in treatment of COVID-19 associated pneumonia in clinical studies. Biosci Trends 14:72-73

Gautret P, Lagier JC, Parola P, Hoang VT, Meddeb L, Mailhe M, Doudier B, Courjon J, Giordanengo V, Vieira VE, Dupont HT, Honore S, Colson P, Chabriere E, La Scola B, Rolain JM, Brouqui P, Raoult D (2020) Hydroxychloroquine and azithromycin as a treatment of COVID-19: results of an open-label non-randomized clinical trial. Int J Antimicrob Agents: 105949

Huang C et al (2020) Clinical features of patients infected with 2019 novel coronavirus in Wuhan, China. Lancet 395:497-506

Khan M, Santhosh SR, Tiwari M, Lakshmana Rao PV, Parida M (2010) Assessment of in vitro prophylactic and therapeutic efficacy of chloroquine against Chikungunya virus in vero cells. J Med Virol 82: $817-824$

Kim ML, Martin WJ, Minigo G, Keeble JL, Garnham AL, Pacini G, Smyth GK, Speed TP, Carapetis J, Wicks IP (2018) Dysregulated IL-1beta-GM-CSF Axis in Acute Rheumatic Fever That Is Limited by Hydroxychloroquine. Circulation 138:2648-2661

Landewe RB, Miltenburg AM, Verdonk MJ, Verweij CL, Breedveld FC, Daha MR, Dijkmans BA (1995) Chloroquine inhibits T cell proliferation by interfering with IL-2 production and responsiveness. Clin Exp Immunol 102:144-151

Ledford H (2020) How does COVID-19 kill? Uncertainty is hampering doctors' ability to choose treatments. Nature 580:311-312

Lenzer J (2020) Covid-19: US gives emergency approval to hydroxychloroquine despite lack of evidence. BMJ 369:m1335 
Liu J, Cao R, Xu M, Wang X, Zhang H, Hu H, Li Y, Hu Z, Zhong W, Wang M (2020a) Hydroxychloroquine, a less toxic derivative of chloroquine, is effective in inhibiting SARS-CoV-2 infection in vitro. Cell Discov 6:16

Liu Z, Long W, Tu M, Chen S, Huang Y, Wang S, Zhou W, Chen D, Zhou L, Wang M, Wu M, Huang Q, Xu H, Zeng W, Guo L (2020b) Lymphocyte subset (CD4+, CD8+) counts reflect the severity of infection and predict the clinical outcomes in patients with COVID-19. J Infect

Mauthe M, Orhon I, Rocchi C, Zhou X, Luhr M, Hijlkema KJ, Coppes RP, Engedal N, Mari M, Reggiori F (2018) Chloroquine inhibits autophagic flux by decreasing autophagosome-lysosome fusion. Autophagy 14:1435-1455

Mehta P, McAuley DF, Brown M, Sanchez E, Tattersall RS, Manson JJ, Hlh Across Speciality Collaboration UK (2020) COVID-19: consider cytokine storm syndromes and immunosuppression. Lancet 395:1033-1034

Muller-Calleja N, Manukyan D, Canisius A, Strand D, Lackner KJ (2017) Hydroxychloroquine inhibits proinflammatory signalling pathways by targeting endosomal NADPH oxidase. Ann Rheum Dis 76:891-897

Oudit GY, Kassiri Z, Patel MP, Chappell M, Butany J, Backx PH, Tsushima RG, Scholey JW, Khokha R, Penninger JM (2007) Angiotensin II-mediated oxidative stress and inflammation mediate the age-dependent cardiomyopathy in ACE2 null mice. Cardiovasc Res 75:29-39

Pedersen SF, Ho YC (2020) SARS-CoV-2: a storm is raging. J Clin Invest

Principi N, Esposito S (2020) Chloroquine or hydroxychloroquine for prophylaxis of COVID-19. Lancet Infect Dis

Rebecca VW et al (2019) PPT1 Promotes Tumor Growth and Is the Molecular Target of Chloroquine Derivatives in Cancer. Cancer Discov 9:220-229

Rempenault C, Combe B, Barnetche T, Gaujoux-Viala C, Lukas C, Morel J, Hua C (2020) Clinical and Structural Efficacy of Hydroxychloroquine in Rheumatoid Arthritis: A Systematic Review. Arthritis Care Res (Hoboken) 72:36-40

Saha RN, Pahan K (2006a) Signals for the induction of nitric oxide synthase in astrocytes. Neurochem Int 49:154-163

Saha RN, Pahan K (2006b) Regulation of inducible nitric oxide synthase gene in glial cells. Antioxid Redox Signal 8:929-947

Schrezenmeier E, Dorner T (2020) Mechanisms of action of hydroxychloroquine and chloroquine: implications for rheumatology. Nat Rev Rheumatol 16:155-166

Seitz M, Valbracht J, Quach J, Lotz M (2003) Gold sodium thiomalate and chloroquine inhibit cytokine production in monocytic THP-1 cells through distinct transcriptional and posttranslational mechanisms. J Clin Immunol 23:477-484

Stower H (2020) Spread of SARS-CoV-2. Nat Med 26:465

Sundelin SP, Terman A (2002) Different effects of chloroquine and hydroxychloroquine on lysosomal function in cultured retinal pigment epithelial cells. APMIS 110:481-489
Taccone FS, Gorham J, Vincent JL (2020) Hydroxychloroquine in the management of critically ill patients with COVID-19: the need for an evidence base. Lancet Respir Med

Tricou V, Minh NN, Van TP, Lee SJ, Farrar J, Wills B, Tran HT, Simmons CP (2010) A randomized controlled trial of chloroquine for the treatment of dengue in Vietnamese adults. PLoS Negl Trop Dis 4: e785

Vickers C, Hales P, Kaushik V, Dick L, Gavin J, Tang J, Godbout K, Parsons T, Baronas E, Hsieh F, Acton S, Patane M, Nichols A, Tummino P (2002) Hydrolysis of biological peptides by human angiotensin-converting enzyme-related carboxypeptidase. J Biol Chem 277:14838-14843

Wang H, Yang P, Liu K, Guo F, Zhang Y, Zhang G, Jiang C (2008) SARS coronavirus entry into host cells through a novel clathrin- and caveolae-independent endocytic pathway. Cell Res 18:290-301

Wang W, Bodiga S, Das SK, Lo J, Patel V, Oudit GY (2012) Role of ACE2 in diastolic and systolic heart failure. Heart Fail Rev 17:683691

Wang F, Nie J, Wang H, Zhao Q, Xiong Y, Deng L, Song S, Ma Z, Mo P, Zhang Y (2020) Characteristics of peripheral lymphocyte subset alteration in COVID-19 pneumonia. J Infect Dis

Watanabe T, Jono H, Han J, Lim DJ, Li JD (2004) Synergistic activation of NF-kappaB by nontypeable Haemophilus influenzae and tumor necrosis factor alpha. Proc Natl Acad Sci U S A 101:3563-3568

Wu F, Zhao S, Yu B, Chen YM, Wang W, Song ZG, Hu Y, Tao ZW, Tian JH, Pei YY, Yuan ML, Zhang YL, Dai FH, Liu Y, Wang QM, Zheng JJ, Xu L, Holmes EC, Zhang YZ (2020) Author Correction: A new coronavirus associated with human respiratory disease in China. Nature 580:E7

Yamamoto K, Ohishi M, Katsuya T, Ito N, Ikushima M, Kaibe M, Tatara Y, Shiota A, Sugano S, Takeda S, Rakugi H, Ogihara T (2006) Deletion of angiotensin-converting enzyme 2 accelerates pressure overload-induced cardiac dysfunction by increasing local angioten$\sin$ II. Hypertension 47:718-726

Yang ZY, Huang Y, Ganesh L, Leung K, Kong WP, Schwartz O, Subbarao K, Nabel GJ (2004) pH-dependent entry of severe acute respiratory syndrome coronavirus is mediated by the spike glycoprotein and enhanced by dendritic cell transfer through DC-SIGN. J Virol 78:5642-5650

Yao X, Ye F, Zhang M, Cui C, Huang B, Niu P, Liu X, Zhao L, Dong E, Song C, Zhan S, Lu R, Li H, Tan W, Liu D (2020) In Vitro Antiviral Activity and Projection of Optimized Dosing Design of Hydroxychloroquine for the Treatment of Severe Acute Respiratory Syndrome Coronavirus 2 (SARS-CoV-2). Clin Infect Dis

Zaman MA, Oparil S, Calhoun DA (2002) Drugs targeting the reninangiotensin-aldosterone system. Nat Rev Drug Discov 1:621-636

Publisher's Note Springer Nature remains neutral with regard to jurisdictional claims in published maps and institutional affiliations. 